\title{
ROLE OF REGRET AVERSION AND LOSS AVERSION EMOTIONAL BIASES IN DETERMINING INDIVIDUAL INVESTORS' TRADING FREQUENCY: MODERATING EFFECTS OF RISK PERCEPTION
}

\author{
Sayed Ibtasam Shafqat ${ }^{1 *}$, Imran Riaz Malik ${ }^{2}$ \\ ${ }^{1 *}$ Ph.D., Scholar, Iqra University Islamabad Campus, Pakistan; ${ }^{2}$ Associate Professor, Iqra University Islamabad Campus, \\ Pakistan. \\ Email: *ibtasamanum@gmail.com
}

Article History: Received on $9^{\text {th }}$ June 2021, Revised on $27^{\text {th }}$ June 2021, Published on $29^{\text {th }}$ June 2021

\begin{abstract}
Purpose: This study aims to investigate the moderating effect of risk perception on the relationship among emotional biases (i.e., regret aversion and loss aversion) and the trading frequency of individual investors in the context of the Pakistan Stock Exchange (PSX).

Approach / Methodology: This study is conducted under the philosophical assumptions of the positivist paradigm and the approach is deductive. The convenience sampling technique is used for sample selection of registered individual investors on the database of PSX. This led the study towards designing a cross-sectional study. Furthermore, 384 questionnaires are used for the collection of primary data from a population of 0.22 million registered PSX individual investors. The direction and degree of relationship among variables of concern are analyzed by the multiple linear regression techniques. The structural Equation Modelling (SEM) technique is used for authentication of moderation results.
\end{abstract}

Findings: The results depict that regret aversion and loss aversion have statistically significant and negative impacts on individual investors' trading frequency. Whereas, risk perception has an insignificant \& positive impact on individual investors' trading frequency. Moreover, risk perception is found to moderate the relationship between these two emotional behavioral biases.

Originality/Value: This current study is a pioneer in developing links between individual investors' trading frequency, loss aversion, regret aversion, and risk perception. The article also contributes to the literature of behavioral finance, specifically while understanding the role of emotional biases in investment strategies. So, this article engenders the reader's thoughtfulness to find plausible explanations in minimizing the impact of emotional biases in trading frequency and decision-making of individual investors.

Implications: This study implies that emotional biases and risk perception cause and moderate the magnitude of the trading frequency of individual investors. The regulatory bodies such as the Securities and Exchange Commission of Pakistan (SECP) and PSX can launch training programs for individual investors to train them in coping up with such emotional biases and risk perception. This might result in the enhancement of the market capitalization of the stock market.

Keywords: Behavioral Finance, Regret Aversion, Loss Aversion, Risk Perception, Trading Frequency.

\section{INTRODUCTION}

For decades, the lifeline of an economic system has been relying on the sculpture of wealth management. Saying so, wealth maximization is the vision of almost every corporation in the capitalistic environment. This enhances the value of investments and entrepreneurship. Defining features of investments and entrepreneurship rely upon choosing the right opportunities for persuasion and exploitation (Shane and Venkataraman 2000). In doing so, conventional and behavioral finance guides the individual and institutional investors in making the right choices for them. Past studies show that investors use different theories and models of conventional finance for appraisal of risk and linked expected returns while trading in stocks (Arora and Kumari 2015). Several assumptions and theories of conventional finance have been used by renowned scholars to elucidate the finance models. Classical or traditional economics/finance theories reflect that investors make rational decisions to enhance their returns (Cilingiroğlu, Rahman, et al. 2011). Whereas, in reality, irrational behaviors are displayed by investors while trading in financial markets i.e., investors trade unreasonably like they buy certain stocks without knowing their fundamental value just because their good friends are buying those stock (Benjamin, Virani, et al. 2018). Experts suggest that this irrational part has a deep linkage with cognitive and emotional behavioral biases of investors which can only be studied under behavioral finance theories. In consonance with (Alrabadi, Al-Abdallah, et al. 2018) behavioral finance is different from conventional finance as in this investors are considered to depict irrational and psychologically biased behavior which ultimately creates an impact on individual investors trading frequency.

The basic concept of behavioral finance was transpired in the famous book of Adam Smith "Moral Thought System" in 1759 where he says that irrational behavior is displayed when some investor attains some breakthrough in investments. Behavioral finance defines bias as the propensity of taking investment decisions when some fastidious investor is already persuaded by any underlying belief (Shefrin 2016). (Özen and Ersoy 2019) documented and defined individual 
investor as an investor who likes to trade on his behalf and same trade at small levels comparatively.

Investors' decision-making criterion remains the main focus of attention in the literature of conventional and behavioral finance. Thorough research work in recent times has reconnoitered many psychological biases and also analyzed their influence on individual investors' investment decisions. According to behavioral finance specialists, every investor has different behavioral biases due to his unique personality. These behavioral biases can prevent investors from making investments rationally, which may have unpleasant repercussions on investors' trading frequency due to the irrational decision-making process (Acciarini, Brunetta, et al. 2020). The pioneering and famous prospect theory of behavioral finance states that investors rely on limited information by using heuristics, or biases, which simplify their decisions at cost of factual information use (Kahneman 2007). On the other side, traditional financial theories disregard such biases and heuristics; it assumes investors are rational, and they make investments rationally (Pompian 2012). Market efficiency theory holds the value of bedrock in traditional finance. It reflects that markets are efficient i.e., even if investors do make errors or mistakes; due to certain behavioral biases, the price of securities or stocks still represent fair value (Cassidy 2010). Efficient markets interpret investors as rational, consistent, and unbiased actors in making optimal investment decisions, with no involvement of their emotions or psyche (Delcey 2019). The behavioral finance concept has continually cropped up from 1990 onwards, along with intensifying evidence that the efficient markets hypothesis theory is not sufficient to explain irrational behavior of investors and anomalies in the market (Cornicello 2004). (Nikiforow 2010) documented in a study related to performance and trading of fund managers that most proficient training is even insufficient in altering the irrational behavior of humans in making investments.

Adam Smith in his book "Moral Thought System" laid the foundation of regret aversion and loss aversion biases by documenting that individuals feel regret and pain while moving from a good situation to a bad condition (Özen and Ersoy 2019). Individual investor's trading frequency is influenced by many factors like bounded rationality, income level, cognitive and emotional weakness, financial knowledge, limited information, intuitive reasoning, demographics, fundamental heuristics, and qualification of investors. The relationship between trading frequency and psychological biases has been explained in many theories. Key theories in this regard include prospect theory, cognitive theory, and bounded rationality theory. The prospect theory which laid the foundation of behavioral finance was presented by (Kahneman and Tversky 1979). This theory states that trading frequency relies on investment decisions that are made based on losses and gains by investors. Investors value losses and gains differently, and both are calculated by certain benchmarks or reference points.

Numerous studies like (Awais and Estes 2019), (Khan 2016, Khan 2017), (Shah, Ahmad, et al. 2018), (Rasool and Ullah 2020), and (Shah and Malik 2021) have reported that, in reality, markets are inefficient due to individual biases along with persisting anomalies in Pakistan. (Rasool and Ullah 2020) highlighted in his research that to explain and understand individual investors' choices and trading frequency, it is mandatory to examine certain emotional behavioral biases that influence investor's performance in the emerging market like PSX.

The meta-analysis of behavioral finance studies conducted in Pakistan like (Shah, Ahmad, et al. 2018), (Awais and Estes 2019), and (Shah and Malik 2021) reflect that majority of researchers in Pakistan has explored the combined impact of both types of behavioral biases i.e., cognitive and emotional biases on investors performance and decision-making process. However, the study on exploration of emotional biases only and their impact on the trading frequency which is an important proxy of individual investor's decision making is still a muddled area in Pakistan. The entire debate on various aspects of trading frequency has not produced objective rules or theories to date. The direct relationship between emotional behavioral biases and trading frequency has already been examined in few studies in past but they paid less concern to those underlying means by the help of which such relationships are induced more in real (Baker and Puttonen 2017). Furthermore, (Rosenberg 1968) highlighted in contingency theory that bivariate relationships rely on the involvement of a third variable. Therefore, it is very pertinent to introduce new moderators in the understanding of psychological factors which affect investors' trading frequency. (Shah, Ahmad, et al. 2018) propose that it is imperative to explore those variables which moderate the relationship between behavioral biases and individual investors' trading frequency of PSX. Risk perception varies among individual or institutional investors. This study theorizes that risk perception moderates the relationship between biases and the trading frequency of individual investors. Risk perception is an important moderator of this research, which is not tested and explored before in such an underlying mechanism.

This research relies on the theoretical fields of emotional and cognitive psychology and emotional-driven behavioral biases which are combined with some investment management literature. So, a theoretical contribution is being made by this study by apprising on insights in individual investors' trading frequency of PSX and further exploring how individual investors' trading frequency is affected by these two selected emotional biases along with the moderation impact of risk perception. This study has both theoretical and vital practical implications, as individual investors trade in such environments which are normally characterized by a great level of insecurity and uncertainty (Jain, Jain, et al. 2015). Emerging markets such as Pakistan and India are bound to possess such irrational behavior depiction of investors. The majority of earlier studies conducted in the developed markets have been concentrating on exploring individualistic cultures in developed financial markets. Empirical research is essential to develop an understanding of the individual investors' behaviors in collectivist-dominated cultures for increasing financial stability in developing countries' stock markets. Due to differences in such contextual paradigms (collectivist vs individualist) research conducted in any 
developed country may not be generalized to any Asian country like Pakistan or India. This leaves room to fill the gap in the current literature by contributing contextually and by using data collected from individual investors of PSX. In Pakistan, investors are not completely aware of existing behavioral biases while trading, so this article will contribute to understanding selected emotional biases which may guide in future for effective decisions in the case of public policy by the Securities and Exchange Commission of Pakistan (SECP). It may also be useful in bringing awareness to individual investors by understanding these emotional biases and in gauging the influence of their emotional factors on their performance and trading frequency.

After the introduction in the $1^{\text {st }}$ section of the paper, the appended $2^{\text {nd }}$ section discusses the relevant literature on the main variables of the study i.e., regret aversion, loss aversion biases, and risk perception. Section 3 presents the data and outlines the methodology employed in this study to achieve the stated objective. Section 4 reports results, analysis, and develops discussion on the reported results of the study. Section 5 concludes the study while presenting recommendations and directions for future research.

\section{LITERATURE REVIEW}

Voluminous literature is available on the behavioral biases, irrational behavior of investors, and trading frequency of individual investors. Many researchers have put their best in investigating the impact of emotional and cognitive biases on the performance, decision-making, and trading frequency of individual investors in different environments and cultures. This leads us to the next section of the study, which presents a theoretical and empirical review of prior studies; mainly considering the linkage of regret aversion and loss aversion emotional biases along with the vital role of risk perception on individual investors' trading frequency.

\section{Individual Investors' Trading Frequency}

The Individual investors and their trading frequency and linkages among these two remain the topic of discussion in this section. For instance, $\left(\mathrm{Hu}^{*}\right.$ and $\left.\mathrm{Chan} 2005\right)$ explained trading frequency as the number of investments performed in a particular time interval. (Özen and Ersoy 2019) documented and defined individual investor as an investor who likes to trade on his behalf. From earlier studies, (Sharpe 1964) found out that individual investors like to take optimum decisions while trading and doing investments. On the other hand, these topics are linked with the presence of emotional biases as well. (Jain, Jain, et al. 2015) highlighted that investment decisions of individual investors' trading frequency have a deep linkage with existing behavioral biases in individual investor personality. On similar lines, (Barber and Odean 2013) in their study on individual investors mentioned that trading frequency is an important proxy for analyzing individual investors' decision-making processes and patterns.

The study of behavioral finance literature reflects that individual investors do not behave rationally and the same has been proven through empirical evidence in many studies. (Barberis and Thaler 2003) postulated few models to explain excess volatility in stocks and excessive trading of investor's stock return predictability with the help of prospect theory. It is highlighted in many studies that high-frequency traders dominate in the financial markets. (Li, Cooper et al. 2018) stated that systematic instabilities and anomalies in stock markets dominated by the high trading frequency of investors are now becoming a principal concern for regulatory authorities after the 2010 Flash Crash. Furthermore, (Bollerslev and Todorov 2011) and (Jung, Lee, et al. 2009) stated in their research that the emergence of emotional behavioral finance biases has introduced individual investor behavior (investor psychology) as a factor affecting the trading frequency and asset returns. It is obvious from the studies cited above that it is pertinent to identify the causes of investors' trading frequency in emerging as well as developed markets.

\section{Emotional Biases}

Behavioral biases of all market participants discriminate them from rational actors as explained in classical economic theory. All these behavioral biases explaining individual investor's behavior are covered under Behavioral Finance Micro (Ricciardi 2008). The extant research work on behaviors of individual investors categorizes these biases by relating them to some meaningful framework. Few studies define these biases as heuristics (rules of thumb), while few call them judgments, beliefs, or preferences; still, the majority of scholars segregate them on cognitive and emotional lines. (Pompian 2011) segregated biases on cognitive and emotional bases and defined emotional biases as "Biases which occur spontaneously when an individual behaves, while relying on personal feelings at the time of decisions or making an investment". He further adds that "If commitment and certain facts specify any emotional affiliation while trading or making decisions challenge, then those facts and commitments pose emotional threats". Numerous researchers in past have analyzed the impact of emotional biases and their outcome on individual investors' behavior, trading frequency, and decision making while doing investments in the stock exchange (Fenton-O'Creevy, Lins, et al. 2012), (Duxbury 2015), and (Sutha 2016).

According to (Kahneman and Riepe 1998) "individual investors may always be directed by reflecting an accurate picture of their emotional personality that influences their investment decisions: their occasionally imperfect assessment of their interests due to emotions, and the perimeters of their capacity to seek advice from others related to their emotional affiliation's". (Shefrin 2010) explored that the root cause of the 2008 financial crisis was psychological. In all the events which caused these crisis, heuristics, framing effects and emotional behavioral biases were glaring reasons 
that strongly influenced the judgments and decisions of financial firms, government regulators, rating agencies, elected officials and lastly individual investors.

\section{Regret Aversion and Individual Investor Trading Frequency}

Regret aversion is an emotional bias that is comparatively developed late in any investor. Individual investors occasionally posit that a negative outcome may have been avoided if a different course of action has been selected while trading (Ady 2019). Regret theory (Loomes and Sugden 1982) is a vital theory of emotional biases in behavioral finance which reflects that investors mostly care about what they could have realized in the past if a different option would have been chosen (Ady 2019). This theory has been tested in several studies. For instance, (Deuskar, Pan, et al. 2020) investigated the impact of regret aversion emotional bias on investors' trading frequency in China and confirmed that this impact effect is stronger in case of any taken action rather than inaction. Neuroscience also backs the importance of regret in the decisions of human beings and the psychological area of regret in all types of decision-making is extensively investigated with empirical evidence in past studies (Camille, Coricelli, et al. 2004, Bourgeois-Gironde 2010). Similarly, in neuroticism relationship of regret with individual investors' trading behavior is studied in past studies .e.g., (Fung and Durand 2014) report that if individual investors with high neuroticism invest in portfolios with certain outcomes that strengthen the negative emotions linked with trait; the actions they take in response to mitigate these disturbing incitements are mostly self-defeating and ineffective. As per (Pompian 2011) individual investors become victims of regret aversion bias and avoid investments either due to errors of commission or errors of omission. In general, such behavior is displayed by some individual investors in the shape of reference-dependent utility as investors mostly do compare their investments with other investments in their state of mind (Diecidue and Somasundaram 2017). (Engelbrecht-Wiggans, Haruvy et al. 2007) determined in their study that individual investors do regret in both scenarios i.e., either in stable or even non-stable environments. (Awais and Estes 2019) conducted a detailed study on the antecedents of regret aversion bias in PSX and they documented after thorough analysis that lack of analyzing ability, errors of commission, regret aversion, inappropriate information \& conservatism are key contributing factors in the development of emotional biases in Pakistan. Similarly, a recent study by (Shah and Malik 2021) documented that regret aversion harms the trading frequency of PSX registered individual investors.

After doing above mentioned review of relevant literature, the following is hypothesized for its empirical testing.

H1: Regret Aversion has a significant negative impact on individual investors' trading frequency in PSX.

\section{Loss Aversion and Individual Investor Trading Frequency}

loss aversion emotional bias is a part of the theory of prospects (Kahneman and Tversky 1979). These two renowned scholars of behavioral finance thoroughly explained the loss aversion phenomenon in prospect theory and also laid the foundation of emotional biases. Loss aversion was described as an S-shaped kind of value function in this theory where investors weigh all possible profits and losses in connection to a set benchmark and investors show the propensity of being extra conscious to losses contrary to possible profits.

Many scholars have explained individual investor's loss-averse behavior and trading preferences (Ben-Rephael, Kandel, et al. 2012) and (Gao, Li et al. 2017). These scholars trusted on normative models where individual investors maximized the utility function in relevance to some predetermined criteria. In a classic scenario of loss aversion bias, an individual investor will always dread to sell those securities in his portfolio, which have not performed well (Elhussein and Abdelgadir 2020). Similarly, (Lee and Veld-Merkoulova 2016) documented that an individual investor with loss-averse emotional behavioral bias in his personality will always prefer investment options with low expected losses as compared to gains. (Yao and Li 2013) highlighted the endogenous loss aversion emotional bias in an individual investor in a situation where the degree of incomplete information touches a certain threshold. He states that this bias appears more prominently in a scenario where information turns out to be sparser.

The asset allocation pattern and trading of a linear loss-averse investor were studied by (Fortin and Hlouskova 2011) and the same was compared with traditional and conditional value-at-risk investors. They found that under asymmetric dependency, loss-averse investors mostly outperform mean-variance portfolio investors, provided these investors are amply loss-averse. (Leung and Tsang 2013) used a data set that contained transactions in Hong Kong of transactions of investors in the real estate sector from 1992 to 2006. They found that loss aversion bias has an impact on the investors' trading behavior. Their results indicated that loss aversion and anchoring bias contribute to the trading choices and cyclicality of the housing market. (Durand, Fung, et al. 2019) reported that as neuroticism increases, investor's propensity to unveil myopic loss aversion increases, and the variance among the competition among the infrequent and frequent treatments of investors become greater. Similarly, (Bouteska and Regaieg 2018) found that loss aversion harms investors' trading frequency in the US market and that the market responds negatively to this emotional bias. In the scenario of Pakistan, a study conducted by (KHAN, Azeem, et al. 2017) documented after thorough analysis that loss aversion has a negative and significant impact on the investment decisions of individual investors. A recent study by (Shah and Malik 2021) also explored that loss aversion harms the trading frequency of PSX registered individual investors.

After doing above mentioned review of relevant literature, the following is hypothesized for its empirical testing. 
H2: Loss Aversion has a significant negative impact on individual investors' trading frequency in PSX.

\section{Risk Perception}

Traditional and behavioral finance defines risk differently. According to the behavioral finance perspective, risk perception is a subjective judgment of investors, which they make regarding the characteristics and gravity of a risk (Ricciardi 2008). The study of all renowned theories of risk perception like situational rationality theory habituated action theory, and protection motivated theory reflects that people rely on certain experiences, values, and beliefs while assessing risk. As per (Schmidt 2004) habituated action theory reflects that rapid trading in increased risk behavior without facing a negative outcome mostly decreases the risk perceptions connected with this behavior. Similarly, (Lam and Ozorio 2015) reported that risk perception can be used to differentiate an overall decision in Chinese students that it is risky as compared to other available alternatives. Similarly, (Jandail 2014) stated that the risk perception of investors is an important factor that influences their respective investment decisions.

\section{Risk Perception and Trading Frequency}

(Hoffmann, Post, et al. 2015) investigated the impact of risk perception on individual investors' trading frequency and behavior and confirmed that perceptions of individual investors are important drivers of actual trading and risk-taking behavior. Some researchers explored that investors with more return expectations are likely to trade more to have higher turnover and profits. Similarly, (Ainia and Lutfi 2019) documented that decisions of investors and trading frequency of investments are impressively influenced by risk perception and previously earned profit. The case of research studies conducted on investors of Pakistan (Shafi, Hussain, et al. 2011) and (Farooq and Sajid 2015) documented that the trading behavior of investors in the equity market is negatively influenced by their risk perceptions.

After doing above mentioned review of relevant literature, the following is hypothesized for its empirical testing.

H3: Risk perceptions of individual investors have a significant negative influence on trading frequency in PSX.

\section{Moderation role of Risk Perception}

The moderating role of risk perception between behavioral biases and investors' trading behavior is reflected in the previous studies. (Khan 2016, Khan 2017) have analyzed the moderating role of risk perception along with selected emotional biases and found that risk perception strengthens this relationship of emotional behavioral biases and investment decisions of registered investors. Similarly, a recent study by (Shehata, Abdeljawad, et al. 2021) used risk perception as a moderator while finding its moderating impact on the Saudi Arabian stock market investors' and documented that risk perception has a negative impact on investors intentions. Whereas, the findings of (Trang and Tho 2017) were in contrast to the above-mentioned study and reflected that the greater the perceived risk, the more the investors are satisfied in their investment decisions. (Ferreira 2018) reports that investors' risk perceptions and attitudes are relying on selected financial models. These models are used in describing perceived risks and investment behaviors and are explained by subjective and objective risk propensity. Another important study by (Ademola, Musa, et al. 2019) explored that risk perception plays a role of significant moderator in individual investor's trading experiences and decisions.

After doing above mentioned review of relevant literature, the following is hypothesized for its empirical testing.

H4: Risk perception moderates the association between regret aversion and trading frequency of individual investors in PSX.

H5: Risk perception moderates the association between loss aversion and trading frequency of individual investors in PSX.

\section{Theoretical Framework}

The literature review reflects that regret aversion and loss aversion emotional behavioral biases unquestionably have an impact on the trading frequency of individual investors while investing in the stock markets. Keeping in view the gap analysis, theories, and evidence from past researches, the conceptual framework (Figure 1) is derived for empirically examining the impact of regret aversion and loss aversion emotional behavioral biases on individual investors' trading frequency along with moderating role of risk perception.

\section{DATA AND METHODOLOGY}

This section presents the data description and the econometric technique for analyzing the proposed hypothesis. The following subsections present the same in detail:

\section{The population of the Study}

The study population comprises 0.22 million individual investors registered in PSX (2020). Although this study is carried out in Pakistan and focuses on the trading frequency of individual investors of PSX, it may also have applicability to developing countries' investor trading frequency in their respective stock exchanges. 


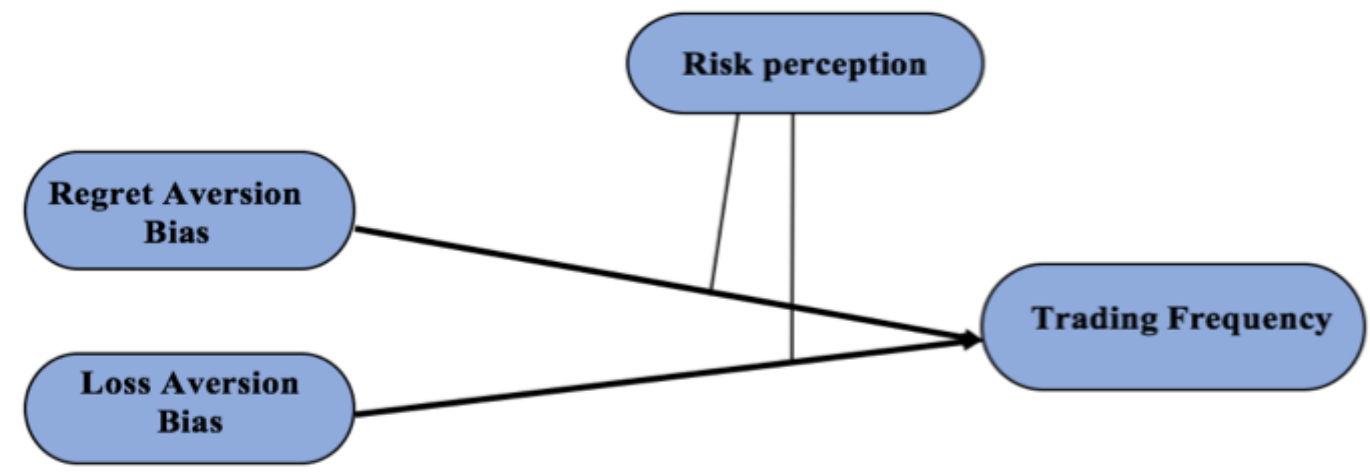

Figure 1: Conceptual framework

\section{Sampling and Data Collection}

This study is conducted in the positivistic paradigm and the results of this study are reliable with assumptions of the

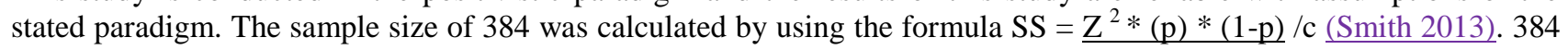
questionnaires were distributed for collecting the data from the respondents. 242 questionnaires were returned from the respondents and out of these 62 questionnaires were rejected as being wrongly filled by the respondents. 180 questionnaires with a response rate of 65\% were used for data analysis. It is highlighted by (Hair 2009) that, in the case of quantitative research, data obtained from a minimum number of 100 respondents is good enough for statistical data analysis and produces reliable results. It was confirmed by reviewing the methodology of previous studies like (Shah, Ahmad, et al. 2018), (Shah and Malik 2021), and (Khan 2016, Khan 2017) that in all these studies the sample size varied from 140 to 265. Convenience sampling was used for collecting data from all the respondents instead of random sampling as access to a complete population frame was not possible. Furthermore, for ease and comfort of respondents and keeping in view the time and cost element in mind, the self-reported questionnaire method was used for data collection. Similarly, tenure for filling out all questionnaires was from March 2020 to November 2020.

\section{Econometric Technique}

The statistical expression of the model is as appended below: -

$T F=\alpha+\beta 1 R A+\beta 2 L A+\beta 3 R P+\beta 4 R A R P+\beta 5 L A R P+\epsilon$

In the above linear equation, the trading frequency (dependent variable) of registered individual investors is represented by TF whereas, RA and LA represent regret aversion and loss aversion biases which are used as independent variables in our study. Risk perception is a moderating variable and is reflected as RP. Similarly, $€$ represents the error term of our equation.

\section{Research Approach \& Design}

This study is conducted in the positivistic paradigm and the results of this study are reliable with assumptions of the stated paradigm. A deductive and correlational study approach was preferred on inductive approach because as per (Sekaran and Bougie 2016) in the deductive approach researchers rely on existing theory and then after logical generalization and discussion they move to some conclusion. Furthermore, research proceeding focuses on testing of hypothesis while relying on underlying behavioral finance and psychology theories, and as per (Sekaran and Bougie 2016) testing of hypothesis suggests a better understanding of the existing relationship between variables.

\section{Instrumentation for Data Collection}

Closed-ended questions were used in our study to note down responses from the target population as specified in the questionnaire. Similarly, a Likert scale, starting from one to five reflecting strongly disagree responses to strongly agree responses of respondents was used in this study. The questionnaire of this study comprises of four sections: A to E. Section A is on regret aversion questions where six items were used for measuring the regret aversion bias and questions were adopted from the study of (Kisaka 2015). Sample item of section A is "Is this fear of regretting your investment decisions will likely to continue informing your future decisions or not?" and Cronbach's alpha value of regret aversion was noted as 0.712. Similarly, section B reflects questions on loss aversion bias where five items were used for measuring regret aversion bias, and questions were adopted from the study of (Kisaka 2015). The sample item of section B is "If I have Rs. 500,000 excess, I would prefer to invest in a risky alternative" and Cronbach's alpha value of loss aversion was noted as 0.812 . Section $\mathrm{C}$ is on risk perception questions where seven items were used for measuring risk perception of individual investors and questions were adopted from (Hoffmann, Post, et al. 2015) study. Sample item of section C is "Next month I prefer certainty over uncertainty when investing" and Cronbach's alpha value of risk perception was noted as 0.799 . Section D is related to the trading frequency of individual investors. The trading frequency of individual investors was measured by adopting an instrument from (Graham, Harvey, et al. 2009) study. 
Furthermore, responses for measuring the trading frequency of individual investors were segregated into 5 categories showing investments of individual investors. Sample item of section D is "In general, how often do you trade in the financial markets?" and the value of Cronbach's alpha for trading frequency was 0.874 .

\section{Methods}

After data collection from respondents, their responses were analyzed with help of SPSS and Gretl software. First of all pilot testing including reliability and validity testing like Cronbach's alpha test and convergent validity of research instrument was carried out, then statistical software was used to attain the results for discussion which includes, descriptive statistics, regression analysis, and correlation analysis. To identify gaps for future research (Kumar and Goyal 2015) reviewed all quantitative studies conducted on the investment decision in behavioral finance and revealed that $66 \%$ of studies on investor's decisions have used regression analysis. Consequently, this study also used a regression model to test hypotheses. To test the moderation effect of risk perception method of (Baron and Kenny 1986) was used. The structural Equation Modelling (SEM) technique was also utilized for authenticating the results of moderation. The methods are consistent with previous studies conducted on similar topics like (Shah, Ahmad, et al. 2018), (Khan 2016, Khan 2017), and (Bouteska and Regaieg 2018).

\section{RESULTS \& ANALYSIS}

\section{Pilot and Reliability Testing}

Firstly, 78 questionnaires were delivered for pilot testing by the researcher to respondents i.e., individual investors who are operating in PSX. Out of these 78 questionnaires, 60 questionnaires were returned reflecting a response rate of $76.25 \%$. Among these 60 questionnaires, only 51 were useable, representing a usage rate of $65.25 \%$. Reliability testing was carried out by considering Cronbach's alpha value / F test of all variables and further validating the results through composite reliability and the end validity of the instrument was done by convergent validity test. The pilot testing results indicated that the dependent variable i.e., investors trading frequency has a Cronbach's alpha value equal to 0.62, which showed improvement and reached 0.745 after deleting two categories for measurement of individual investors trading frequency. The results (Table 1) for Cronbach's alpha value of all variables were found to be greater than 0.7. Similarly, table 1 also reflects that convergent validity also names as AVE (Average Variance Extracted) values are ranged from 0.51 to 0.75 . It was suggested by (Hair, Anderson, et al. 2010) that composite reliability values of any construct more than 50 reflect that selected items show greater variance than error term. Furthermore, reliability results of composite reliability in table 1 are ranging from 0.71 to 0.82 which reflects that reliability for all the constructs is well within a satisfactory range.

Table 1: Results for reliability analysis

\begin{tabular}{lllllc}
\hline Variables & No of items & Cronbach's alpha value & F(sig) & CR & AVE \\
\hline Loss aversion & 4 & 0.812 & $9.673(0.000)$ & 0.785 & 0.513 \\
\hline Regret aversion & 5 & 0.712 & $11.673(0.000)$ & 0.713 & 0.612 \\
\hline Risk perception & 7 & 0.799 & $16.673(0.011)$ & 0.816 & 0.633 \\
\hline Trading Frequency & 3 & 0.874 & $12.673(0.001)$ & 0.886 & 0.521 \\
\hline Note(s): CR = composite reliability and AVE = average variance extracted & & \\
\hline
\end{tabular}

\section{Descriptive Statistics}

Table 2 reflects descriptive statistics related to the demographics i.e., the frequency distribution of age, gender, and experience:

Table 2: Demographic statistics

\begin{tabular}{lll}
\hline & Frequency & Percent \\
\hline Gender & & \\
\hline Female & 20 & 11.1 \\
\hline $\begin{array}{l}\text { Male } \\
\text { Age }\end{array}$ & 160 & 88.9 \\
\hline Less than 25 & 14 & 7.7 \\
\hline 20-30 years & 24 & 13.6 \\
\hline 31-40 years & 49 & 27.9 \\
\hline 41-50 years & 21 & 12.7 \\
\hline 51-60 years & 40 & 22.5 \\
Experience & & \\
\hline Less than 1year & 31 & 17.1 \\
\hline 1-10 years & 29 & 16.2 \\
\hline 11-15 years & 40 & 22.7 \\
\hline 16-20 years & 35 & 19.4 \\
\hline
\end{tabular}




\begin{tabular}{ll}
\hline $\begin{array}{l}21 \text { years and above } \\
\text { Note(s): } \mathbf{N}=\mathbf{1 8 0}\end{array}$ & 45 \\
\hline
\end{tabular}

Table 2 reflects that most respondents were males as among 180 individual investors 160 respondents which makes 88.9 $\%$ of respondents are males and only 20 respondents $(11.1 \%)$ are females in the entire study. Similarly, results of demographics statistics reflect that most registered individual investors are between 31-40 (28\%) years of age and 51-60 (20.5\%) years of age. Similarly, the lowest percentage of registered individual investors are the ones having age less than 25 years (7.7\%). Likewise, 24 registered individual investors out of 180 are of age 20-39 years and 21 investors out of 180 registered individual investors are of age $41-50$ years which are making $12.7 \%$ of total respondents. Furthermore, table 2 of the article also indicates that the majority of registered individual investors are having experience of 21 years and above (24\%). The lowest percentage of registered individual investors are the ones who have experience of 1-10 years (16.2\%). Moreover, 35 individual investors out of 180 are having experience of 16-20 years which is making 19.4 $\%$ of the total respondents.

\section{Correlation Analysis}

The correlations among selected variables and results for mean and standard deviations of variables are reflected in Table 3. Analysis of this table depicts that loss aversion is negatively linked with the trading frequency of individual investors, with a Pearson's correlation coefficient of $r$ is -0.202 and it is significant at $p<0.01$; regret aversion with a Pearson's correlation coefficient value of $r$ is -0.221 and it's significant at $p<0.05$. Similarly, the correlation coefficient value of risk perception is -0.191 and it is significant as $p<0.05$. As a whole, this all depicts that, like loss aversion, regret aversion, and risk perception increases then the trading frequency of individual investors of these investors decreases. Findings of correlation analysis are consistent with studies of (Shehata, Abdeljawad, et al. 2021), (Awais and Estes 2019), and (Shah and Malik 2021).

Table 3: Results for Pearson's correlation

\begin{tabular}{llllllll}
\hline Variables & Mean & SD & $\mathbf{1}$ & $\mathbf{2}$ & $\mathbf{3}$ & $\mathbf{4}$ & Sig \\
\hline Trading Frequency & 3.01 & 1.12 & 1 & & & & \\
\hline Loss aversion & 3.32 & 0.912 & $-0.202^{*}$ & 1 & 0.612 & & 0.00 \\
\hline Risk perception & 3.49 & 0.89 & $-0.191 * *$ & 0.216 & 1 & 0.326 & 0.02 \\
\hline Regret aversion & 3.61 & 1.17 & $-0.221 *$ & 0.886 & 0.521 & 1 & 0.00 \\
\hline Note(s): $\mathrm{N}=180 ;{ }^{*} \mathrm{p}<0.01, * * \mathrm{p}<0.05$ & & & & \\
\hline
\end{tabular}

\section{Inferential Statistics}

A hierarchical regression analysis test was performed in two steps for hypothesis testing. At first, selected demographic variables were added as control variables for reporting $R^{2}$ value only. Later, in the second step loss aversion, regret aversion and risk perception, and trading frequency were regressed and tested. Similarly, changes in $R^{2}$ and beta $(\beta)$ values were reported. Variation in $\mathrm{R}^{2}$ denotes that, after controlling demographic variables, $\mathrm{R}^{2}$ values were significantly affected. Moreover, more than $40 \%$ of the variation was not explored in each case.

Firstly, control variables were regressed with investor's trading frequency; the value $\mathrm{R}^{2}$ reflects $11 \%$ of the study dependent variable (trading frequency) is explained with the help of control variables i.e., demographics. Similarly, in the next step, loss aversion, regret aversion, and risk perception were regressed on the trading frequency of individual investors, and the $\mathrm{R}^{2}$ value i.e., 0.59 shows that about $59 \%$ of the variation in trading frequency is caused by loss aversion, regret aversion, and risk perception.

\section{Individual Investors' Trading Frequency}

It was hypothesized in the first three hypotheses of the literature review that loss aversion, regret aversion, and risk perception would be negatively linked with individual investor's trading frequency. To test the same, researchers regressed individual investor's trading frequency with loss aversion, regret aversion, and risk perception as depicted in Table 4. Analysis of results reflects that regret aversion $(\beta=-0.29 \& \mathrm{p}<0.001)$ is a significant predictor of individual investor's trading frequency which supports article H1. Similarly, analysis of results also reflects that loss aversion ( $\beta=-$ $0.39 \& \mathrm{p}<0.05)$ is a significant predictor of individual investor's trading frequency which also supports article H2. Furthermore, risk perception ( $\beta 0.04 \& p>0.001)$ is not a significant predictor of individual investor's trading frequency and it also has a positive impact on individual investor's trading frequency i.e., opposite direction as predicted in $\mathrm{H} 3$ of the article.

Table 4: Result of regression analysis

\begin{tabular}{llccc}
\hline Predictors & $\boldsymbol{\beta}$ & Trading Frequency $\mathbf{R}^{2}$ & $\boldsymbol{\Delta} \mathbf{R}^{2}$ & Sig \\
\hline Step 1 & & & & \\
Control variables & 0.011 & 0.11 & \\
\hline Step 2 & & & .000 \\
\hline Regret aversion & $-0.29 * * *$ & & 0 \\
\hline
\end{tabular}




\begin{tabular}{|c|c|c|c|}
\hline Loss aversion & $-0.39 * *$ & & .000 \\
\hline Risk perception & 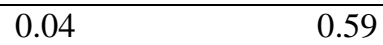 & .0 .35 & .138 \\
\hline
\end{tabular}

\section{Moderation Analysis}

The study used moderation analysis to observe risk perception as a moderator between regret aversion, loss aversion, and trading frequency of individual investors in PSX. The study used (Baron and Kenny 1986) method for doing moderation analysis in our study. Initially, demographics i.e., qualification, gender, experience, and age were added as control variables in the first step. Later, for the second step, we entered regret aversion and loss aversion along with risk perception to predict the impact on the trading frequency of individual investors. Finally, in the last and third steps, the interaction terms among regret aversion, loss aversion trading frequency of individual investors were added.

The results of table 5 depict that regret aversion and loss aversion emotional bias $(\beta=-0.46, p<0.001$ for regret aversion) $\&(\beta=0.41, \mathrm{p}<0.001$ loss aversion) are influencing negatively the trading frequency of individual investors. Likewise, both are significant predictors of trading frequency also. Whereas, risk perception $(\beta=0.05, \mathrm{p}>0.05)$ was an insignificant predictor of individual investor's trading frequency. However, the interaction term of these variables had a significant and negative impact on individual investor's trading frequency i.e., $\beta=0.31 \& p<0.001$ for regret aversion and risk perception. Similarly, the relationship between loss aversion and risk perception as a moderator was found to have a significant and negative impact on individual investor's trading frequency $(\beta=-0.31 \& p<0.001)$. These results support the stated hypothesis i.e., $\mathrm{H} 4 \& \mathrm{H} 5$, which forecasted that risk perception will moderate the association between regret aversion, loss aversion biases, and trading frequency of individual investors.

Table 5: Result of moderation analysis

\begin{tabular}{lllll}
\hline Predictors & B & Trading Frequency $\mathbf{R}^{2}$ & $\mathbf{\Delta \mathbf { R } ^ { 2 }}$ & $\mathbf{S i g}$ \\
\hline $\begin{array}{l}\text { Step 1 } \\
\text { Control variables }\end{array}$ & 0.011 & 0.11 & & \\
\hline Step 2 & & & & \\
\hline Regret aversion & $-0.46^{* * *}$ & 0.49 & & .000 \\
Loss aversion & $-0.41^{* *}$ & & & .000 \\
Risk Perception & 0.05 & & 0.35 & .000 \\
Step 3 & & & 0.39 & .000 \\
\hline RA $\times$ RP & $-0.51 * * *$ & 0.59 & \\
LA $\times$ RP & $-0.59^{* * *}$ & 0.55 & \\
\hline Note $(\mathbf{s}): * * * p<0.001, * * p<0.05 ;$ control variables are age, qualification, gender & \\
\hline
\end{tabular}

\section{Robustness tests}

SEM technique was used for validating the results for the moderation of this study (Table $6 \&$ Fig 4.1). Results of SEM technique indicated that that regret aversion emotional bias $(\beta=-1.387, p=0.002) \&$ loss aversion emotional bias $(\beta=$ $1.287, \mathrm{p}=0.003)$ are significant predictors and are having negative impact on trading frequency of individual investors. Whereas, risk perception ( $\beta=0.0402, p=0.299$ ) was found to be an insignificant predictor of the trading frequency of individual investors. Furthermore, the interaction term of same variables had a significant negative effect on trading frequency of individual investors $(\beta=-0.4895, p=0.0282$ for regret aversion and risk perception moderation effect \& $\beta$ $=-0.4195, p=0.0282$ for loss aversion and risk perception moderation effect). These findings show similarity with regression analysis. So, the SEM technique validates the regression analysis findings of this research.

Table 6: Results for reliability analysis

\begin{tabular}{llllll}
\hline & & B & SE & CR & P value \\
\hline & & & & & 0.002 \\
TF $\longleftarrow$ RA & -1.37 & 0.414 & -3.17 & 0.003 \\
TF & LA & -1.27 & 0.317 & -0.299 & 0.319 \\
TF & RP & 0.042 & 0.497 & 0.347 & 0.002 \\
TF & RA $\times$ RP & 0.4895 & 0.387 & -0.327 & 0.003 \\
TF & RA $\times$ RP & 0.4195 & 0.417 & -0.41 &
\end{tabular}

Note(s): $\mathrm{TF}=$ trading frequency, $\mathrm{RA}=$ regret aversion, $\mathrm{LA}=$ loss aversion $\mathrm{RA} \times \mathrm{RP} \& \mathrm{LA} \times \mathrm{RP}=$ interaction terms

\section{DISCUSSION}

This study expands the prospect theory of behavioral finance theory and habituated action theory of risk perception while analyzing their moderating impact on the trading frequency of individual investors in PSX. The idea of this study was developed from past literature and then we tested responses by hierarchical regression analyses by using statistical software i.e., SPSS and Gretl. Except for results for the risk perception variable in this study, all other results of our 
study provide empirical support to past literature. So, other than the risk perception variable this research does not uncover any surprising results which may be considered dissimilar from past studies conducted on the same topic elsewhere in the world. Furthermore, study findings verify that individual investors of PSX behave irrationally. Loss aversion and regret aversion are significantly negatively associated with individual investor's trading frequency, meaning that loss aversion and regret aversion emotional biases blights the frequency of individual investors' trading. Furthermore, a significant negative relationship between loss aversion and regret aversion emotional biases and individual investors' trading frequency means that individual investors' trading frequency also decreases due to loss aversion and regret aversion emotional biases increment in their personality of individual investors.

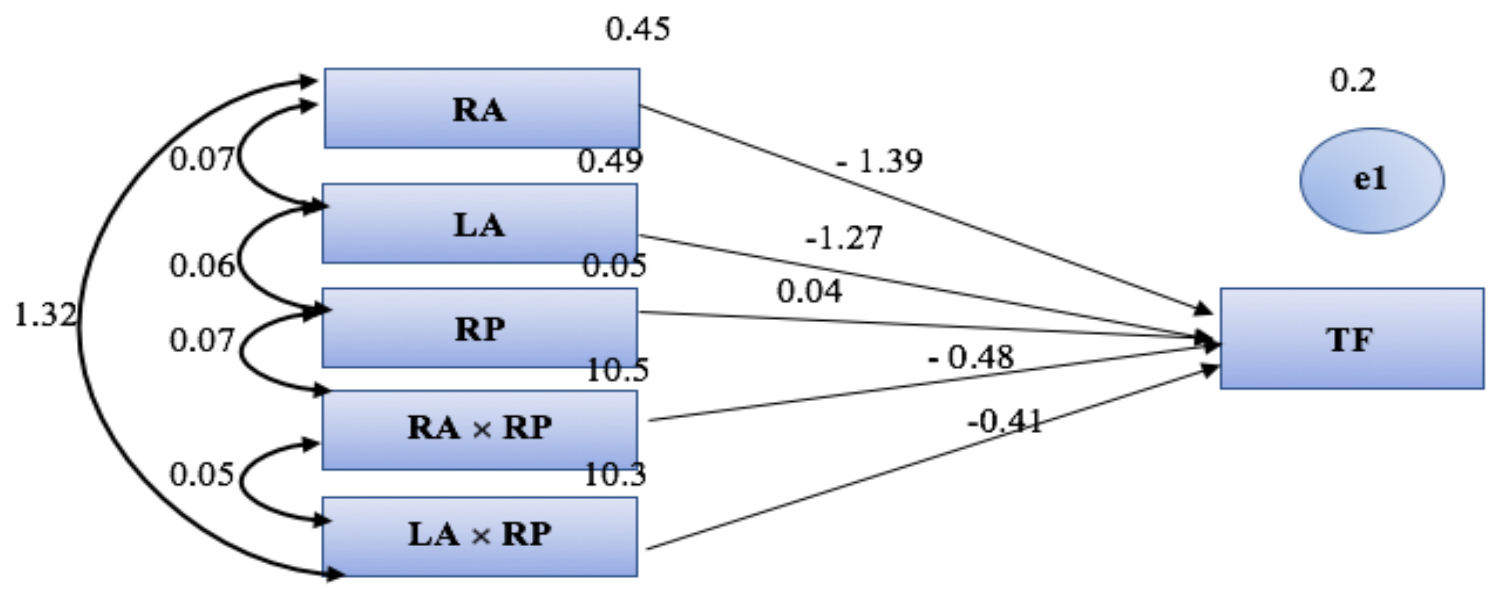

Figure 2: Structural Model

Results for loss aversion and regret aversion emotional biases had similarities with past researches like (Hoffmann, Post, et al. 2015), (Bouteska and Regaieg 2018), (Shah and Malik 2021), (Awais and Estes 2019), and (Lee and VeldMerkoulova 2016). Whereas, risk perception results were contrary to past literature available both in the case of PSX and other developing stock markets e.g., results of (Khan 2016, Khan 2017), (Shehata, Abdeljawad, et al. 2021), and (Shafi, Hussain, et al. 2011) showed that risk perception harms investment trading but this study reflects it has an insignificant and positive impact on the trading frequency of individual investors while investing in PSX. The results and findings of our study on risk perception are contradicted to the prospect theory of behavioral finance (Tversky and Kahneman 1992) which reflects that If a risk is included in individual investors decisions related to the investment performance or trading frequency, then these investors tend to avoid such investment opportunities. So, the positive linkage between risk perception and investment trading frequency shows linkage with the portfolio theory of Markowitz related to risk and return. These results for risk perception show familiarization with a study by (Yuliani, Isnurhadi et al. 2017) who also found a positive linkage of risk perception with investment decisions. Similarly, it shows dissimilarity with the vital (Malmendier and Nagel 2011) study who proposed that bad experiences induce emotional biases and risk perception which make individual investor regret and ultimately they become loss averse which ultimately can decrease investors' willingness to take risks by lessening their risk tolerance.

It is evident from the above discussion that, risk perception variable while interacting with loss aversion and regret aversion emotional biases has no substantial influence on the trading frequency of individual investors. Furthermore, explicitly loss aversion and regret aversion emotional biases have a significant negative impact on the trading frequency of individual investors. The study may also suggest from these findings that when individual investors in Pakistan have emotional behavioral biases of loss aversion and regret aversion in their personalities their trading frequency while investing in PSX is insignificantly affected by risk perception which was used moderator here even being influenced significantly when same variables were used without risk perception.

\section{CONCLUSION \& RECOMMENDATIONS}

\section{Conclusion / Contribution of study}

This paper explores the impact of regret aversion and loss aversion emotional biases on the trading frequency of individual investors while investing in) PSX, along with moderating the impact of risk perception. Researchers provide evidence that supports that the trading frequency of individual investors while investing in PSX is significantly influenced by these two-selected emotional behavioral biases. Individual investors' pessimism induces the presence of regret aversion and loss aversion emotional biases in the personality of a registered investor of PSX as both biases negatively influence the trading frequency of individual investors, whereas individual investors' optimism induces the presence of risk perception as it positively influences individual investors trading frequency. Investor's risk perception has a positive impact on trading frequency, implying that risk perception of PSX may benefit them through greater profitability, higher stock returns, and lower risk performance.

Trading frequency is an important proxy for the measurement of investment decisions. Extreme variations in individual 
investor's trading frequency and performance in developing economies like Pakistan has been observed in past by researchers like (Shah, Ahmad, et al. 2018), (Shah and Malik 2021), (Quddoos, Rafique, et al. 2020), and (Akhtar and Das 2020). Traditional finance has not been able to completely justify such variations to date. More specifically, our article under behavioral finance theories suggests that it is for the better interest of individual investors of PSX and other developing countries' stock markets that individual investors must be less pessimistic and they should protect themselves against loss aversion and regret aversion behavioral biases.

This research is the first of its kind as an impact on trading frequency in developing countries like Pakistan was never explored earlier in such mechanism. Furthermore, the majority of earlier studies conducted in western counties have been concentrating on exploring individualistic cultures in developed financial markets as (Zahera and Bansal 2018) and (Shah, Ahmad, et al. 2018) highlighted in their relevant research work that due to differences in such contextual paradigm (collectivist vs individualist) research conducted in any west country may not be generalized to any Asian country like Pakistan. So, this research will fill the gap in the current literature by contributing contextually. Similarly, It highlights important practical significances for practitioners of finance like for any investor who likes to invest in PSX and other developing countries stock exchanges, for any advisor in an investment firm or even a portfolio manager, for any investment banker and any broker at a stock exchange. Nevertheless, the study is also revenant to academia and all those stakeholders who manage corporate entities and play any role in financial decisions.

\section{POLICY IMPLICATION \& RECOMMENDATIONS}

After the global financial crisis strong regulations of stock and capital markets, understanding of behavioral norms / assumptions and guidance of individual/institutional investors is a serious concern for all policy-makers both in developed and emerging economies (Spindler 2011). This article serves as an acumen to stock market policy-makers like SECP in better understanding the role of emotional behavioral biases in individual investor's trading frequency and other decision-making processes. This research can assist SECP in the segregation of individual investors as per their personality and psychological biases and develop policies that can counter such behavioral factors for smooth market movement. Similarly, it was highlighted and documented in (Montier and Strategy 2002) research related to the irrationality of minds and markets that individual investors can face serious consequences if behavioral biases are ignored in their trading decisions and investment analysis. Accordingly, this study stipulates awareness of emotional biases in investment management, which may be very helpful for policymakers and finance practitioners.

Based on the findings, we suggest that investors should conduct a proper analysis of market opportunities for rational trading frequency instead of relying on emotional behavioral biases as it is inducing them to get involved in irrational trading frequency while investing in PSX. Individual investors' trading frequency may be provoked by regret aversion and loss aversion emotional biases when they observe the decline in some stock of their existing portfolio even they have been holding it for so long. An effective guideline for such investors is that they must ignore all emotions and conduct a proper technical and fundamental analysis of investment opportunities for rational trading frequency. Furthermore, after doing these analyses once they feel convinced about the trading of certain stocks, they should feel confident on their choice and selection of stock, they must stick to their decisions particularly while trading to avoid such significant impact of loss aversion and other emotional biases.

\section{DIRECTIONS FOR FUTURE RESEARCH}

As discussed in previous sections, this study investigated two emotional behavioral biases in the perspective of Pakistan with a small sample size. So, it is recommended research extension for confirming findings of our study may be carried out in the future with a greater sample size along with diverse respondents. Similarly, research extension can also be made by directing research efforts on the appended question:- How do investor's loss aversion and regret aversion biases influence PSX individual investor's performance and trading frequency? Furthermore, it is suggested that more behavioral finance theories should be applied in the exploration of other emotional behavioral biases, which can influence the trading frequency of individual investors as moderated by risk perception.

\section{ACKNOWLEDGEMENT}

The corresponding author is bearing all expenses on his own. Furthermore, he is not attaining any financial / nonfinancial help from any source/organization.

\section{AUTHORS CONTRIBUTION}

All research proceedings of this article are compiled and completed by the first / corresponding author i.e. Sayed Ibtasam Shafqat. Whereas, the second author has been in a supervisory role during all courses of action.

\section{REFERENCES}

1. Acciarini, C., et al. (2020). Cognitive biases and decision-making strategies in times of change: a systematic literature review. Management Decision, 59(3) 638-652. https://doi.org/10.1108/MD-07-2019-1006 
2. Ademola, S. A., et al. (2019). Moderating effect of risk perception on financial knowledge, literacy and investment decision. American International Journal of Economics and Finance Research, 1(1), 34-44. https://doi.org/10.46545/aijefr.v1i1.60

3. Ady, S. U. (2019). Do Young Surabaya‘s Investors Make Rational Investment Decisions? International Journal of Scientific \& Technology Research, 8(7), 319-322.

4. Ainia, N. S. N. and L. Lutfi (2019). The influence of risk perception, risk tolerance, overconfidence, and loss aversion towards investment decision making. Journal of Economics, Business, \& Accountancy Ventura, 21(3): 401-413. https://doi.org/10.14414/jebav.v21i3.1663

5. Akhtar, F. and N. Das (2020). Investor personality and investment performance: from the perspective of psychological traits. Qualitative Research in financial markets, 12(3), 333-352. https://doi.org/10.1108/QRFM$\underline{11-2018-0116}$

6. Alrabadi, D. W. H., et al. (2018). Behavioral biases and investment performance: Does gender matter? Evidence from Amman Stock Exchange. Jordan Journal of Economic Sciences, 5(1), 77-92. https://doi.org /10.35516/1250-005-001-006

7. Arora, M. and S. Kumari (2015). Risk taking in financial decisions as a function of age, gender: mediating role of loss aversion and regret. International Journal of Applied Psychology, 5(4), 83-89.

8. Awais, M. and J. Estes (2019). Antecedents of Regret Aversion Bias of Investors in the Stock Market of Pakistan (PSX) along with the Scale Development on Regret Aversion Bias. City university research journal 9(4), 750-763.

9. Baker, H. K. and V. Puttonen (2017). How Behavioral Biases Can Hurt Your Investing. Investment Traps Exposed, Emerald Publishing Limited. https://doi.org/10.1108/978-1-78714-252-720171004

10. Barber, B. M. and T. Odean (2013). The behavior of individual investors. Handbook of the Economics of Finance, Elsevier, 2, 1533-1570. https://doi.org/10.1016/B978-0-44-459406-8.00022-6

11. Barberis, N. and R. Thaler (2003). A survey of behavioral finance. Handbook of the Economics of Finance, 1, 1053-1128. https://doi.org/10.1016/S1574-0102(03)01027-6

12. Baron, R. M. and D. A. Kenny (1986). The moderator-mediator variable distinction in social psychological research: Conceptual, strategic, and statistical considerations. Journal of personality and social psychology, 51(6), 1173. https://doi.org/10.1037/0022-3514.51.6.1173

13. Ben-Rephael, A., et al. (2012). Measuring investor sentiment with mutual fund flows. Journal of financial Economics, 104(2), 363-382. https://doi.org/10.1016/j.jfineco.2010.08.018

14. Benjamin, E. J., et al. (2018). Heart disease and stroke statistics-2018 update: a report from the American Heart Association. Circulation, 137(12), e67-e492. https://doi.org/10.1161/CIR.0000000000000558

15. Bollerslev, T. and V. Todorov (2011). Tails, fears, and risk premia. The Journal of Finance, 66(6), $2165-2211$. https://doi.org/10.1111/j.1540-6261.2011.01695.x

16. Bourgeois-Gironde, S. (2010). Is neuroeconomics doomed by the reverse inference fallacy? Mind \& Society, 9(2), 229-249. https://doi.org/10.1007/s11299-010-0076-z

17. Bouteska, A. and B. Regaieg (2018). Loss aversion, overconfidence of investors and their impact on market performance evidence from the US stock markets. Journal of Economics, Finance and Administrative Science, 25(50), 451-478. https://doi.org/10.1108/JEFAS-07-2017-0081

18. Camille, N., et al. (2004). The involvement of the orbitofrontal cortex in the experience of regret. Science, 304(5674), 1167-1170. https://doi.org/10.1126/science.1094550

19. Cassidy, J. (2010). Interview with Eugene Fama. The New Yorker, 13(01), 2010.

20. Çilingiroğlu, M., et al. (2011). Spontaneous right coronary artery dissection possibly associated with clonidine transdermal patch. Turk Kardiyol Dern Ars, 39(3), 224-227. https://doi.org/10.5543/tkda.2011.01151

21. Cornicello, G. (2004). Behavioural Finance and speculative bubble. Unpublished master's thesis). Universita Commercial Luigi Bocconi, Milano: Italy.

22. Delcey, T. (2019). Samuelson vs Fama on the efficient market hypothesis: The point of view of expertise. Economia. History, Methodology, Philosophy, 9(1), 37-58. https://doi.org/10.5543/tkda.2011.01151

23. Deuskar, P., et al. (2020). How does regret affect investor behaviour? Evidence from Chinese stock markets. Accounting \& Finance. https://doi.org/10.1111/acfi.12646

24. Diecidue, E. and J. Somasundaram (2017). Regret theory: A new foundation. Journal of Economic Theory, 172, 88-119. https://doi.org/10.1016/j.jet.2017.08.006

25. Durand, R. B., et al. (2019). Myopic loss aversion, personality, and gender. Journal of Behavioral Finance, 20(3), 339-353. https://doi.org/10.1080/15427560.2018.1511562

26. Duxbury, D. (2015). Behavioral finance: insights from experiments II: biases, moods and emotions. Review of Behavioral Finance, 7(2), 151-175. https://doi.org/10.1108/RBF-09-2015-0037

27. Elhussein, N. H. A. and J. N. A. Abdelgadir (2020). Behavioral Bias in Individual Investment Decisions: Is It a Common Phenomenon in Stock Markets? International Journal of Financial Research, 11(6), 25-36. https://doi.org/10.5430/ijfr.v11n6p25

28. Engelbrecht-Wiggans, R., et al. (2007). A comparison of buyer-determined and price-based multiattribute mechanisms. Marketing Science, 26(5), 629-641. https://doi.org/10.1287/mksc.1070.0281 
29. Farooq, A. and M. Sajid (2015). Factors affecting investment decision making: Evidence from equity fund managers and individual investors in Pakistan. Research Journal of Finance and Accounting, 6(9), 2222-1697.

30. Fenton-O'Creevy, M., et al. (2012). Emotion regulation and trader expertise: Heart rate variability on the trading floor. Journal of Neuroscience, Psychology, and Economics, 5(4), 227. https://doi.org/10.10 37/a0030364

31. Ferreira, M. (2018). Cross-country differences in risk attitudes towards financial investment. VoxEU. Org.

32. Fortin, I. and J. Hlouskova (2011). Optimal asset allocation under linear loss aversion. Journal of Banking \& Finance, 35(11), 2974-2990. https://doi.org/10.1016/j.jbankfin.2011.03.023

33. Fung, L. and R. B. Durand (2014). Personality traits, In H. K. Baker \& V. Ricciardi (Eds.), Investor behavior: The psychology of financial planning and investing (pp. 99-115). https://doi.org/10.1002/9781118813454.ch6

34. Gao, J., et al. (2017). When Prospect Theory Preference Meets Mean-Reverting Asset Returns: a Dynamic Asset Allocation Model. Available at SSRN 3161166. https://doi.org/10.2139/ssrn.3161166

35. Graham, J. R., et al. (2009). Investor competence, trading frequency, and home bias. Management Science, 55(7), 1094-1106. https://doi.org/10.1287/mnsc.1090.1009

36. Hair, J., et al. (2010). Multivariate data analysis: A global perspective (Vol. 7): Pearson Upper Saddle River, NJ.

37. Hair, Joseph F., et al.(2019). Multivariate Data Analysis: A Global Perspective. 7th ed. Upper Saddle River: Prentice Hall, 2009.

38. Hoffmann, A. O., et al. (2015). How investor perceptions drive actual trading and risk-taking behavior. Journal of Behavioral Finance, 16(1), 94-103. https://doi.org/10.1080/15427560.2015.1000332

39. Hu*, S.-y. and C. Chan (2005). Trading frequency and noise. Applied Financial Economics Letters, 1(4), 243247. https://doi.org/10.1080/17446540500143624

40. Jain, R., et al. (2015). Behavioral biases in the decision making of individual investors. IUP Journal of Management Research, 14(3), 7.

41. Jandail, R. R. S. (2014). A proposed novel approach for sentiment analysis and opinion mining. International Journal of UbiComp, 5(1/2), 1. https://doi.org/10.5121/iju.2014.5201

42. Jung, C. S., et al. (2009). Can investor heterogeneity be used to explain the cross-section of average stock returns in emerging markets? Journal of International Money and Finance, 28(4), 648-670. https://doi.org/10.1016/i.jimonfin.2009.01.007

43. Kahneman, D. (2007). Daniel Kahneman. In G. Lindzey \& W. M. Runyan (Eds.), A history of psychology in autobiography, Vol. 9, pp. 155-197). American Psychological Association. https://doi.org/10.1037/11571-005

44. Kahneman, D. and M. W. Riepe (1998). Aspects of investor psychology. Journal of portfolio management, 24(4), 52. https://doi.org/10.3905/jpm.1998.409643

45. Kahneman, D. and A. Tversky (1979). On the interpretation of intuitive probability: A reply to Jonathan Cohen, Cognition, 7(4), 409-411. https://doi.org/10.1016/0010-0277(79)90024-6

46. KHAN, A. R., et al. (2017). Impact of Overconfidence and Loss Aversion Biases on Investment Decision: Moderating Role of Risk Perception. International Journal of Transformation in Accounting, Auditing \& Taxation, 1(1).

47. Khan, M. (2017). Impact of availability bias and loss aversion bias on investment decision making, moderating role of risk perception. Management \& Administration (IMPACT: JMDGMA), 1(1), 17-28.

48. Khan, S. (2016). Impact of financial literacy, financial knowledge, moderating role of risk perception on investment decision. Financial Knowledge, Moderating Role of Risk Perception on Investment Decision (February 4, 2016). https://doi.org/10.2139/ssrn.2727890

49. Kisaka, E. K. (2015). The effect of behavioral finance factors on stock investment decisions in Kenya.

50. Kumar, S. and N. Goyal (2015). Behavioural biases in investment decision making-a systematic literature review. Qualitative Research in financial markets. https://doi.org/10.1108/QRFM-07-2014-0022

51. Lam, D. and B. Ozorio (2015). An exploratory study of the relationship between digit ratio, illusion of control, and risk-taking behavior among Chinese college students. Journal of gambling studies, 31(4), 1377-1385. https://doi.org/10.1007/s10899-014-9502-1

52. Lee, B. and Y. Veld-Merkoulova (2016). Myopic loss aversion and stock investments: An empirical study of private investors. Journal of Banking \& Finance, 70, 235-246. https://doi.org/10.1016/j.jbankfin.2016.04.008

53. Leung, T. C. and K. P. Tsang (2013). Anchoring and loss aversion in the housing market: implications on price dynamics. China Economic Review, 24, 42-54. https://doi.org/10.1016/j.chieco.2012.10.003

54. Li, K., et al. (2018). How does high-frequency trading affect low-frequency trading?" Journal of Behavioral Finance 19(2): 235-248. https://doi.org/10.1080/15427560.2017.1376669

55. Loomes, G. and R. Sugden (1982). Regret theory: An alternative theory of rational choice under uncertainty. The economic journal, 92(368), 805-824. https://doi.org/10.2307/2232669

56. Malmendier, U. and S. Nagel (2011). Depression babies: Do macroeconomic experiences affect risk taking? The quarterly journal of economics, 126(1), 373-416. https://doi.org/10.1093/qje/qjq004

57. Montier, J. and G. E. Strategy (2002). Applied behavioural finance: Insights into irrational minds and market. Unpublished manuscript. 
58. Nikiforow, M. (2010). Does training on behavioural finance influence fund managers' perception and behaviour? Applied Financial Economics, 20(7), 515-528. https://doi.org/10.1080/09603100903459832

59. Özen, E. and G. Ersoy (2019). The Impact of Financial Literacy on Cognitive Biases of Individual Investors. Contemporary Issues in Behavioral Finance, Emerald Publishing Limited. https://doi.org/10.1108/S1569$\underline{375920190000101007}$

60. Pakistan stock exchange limited. (2020). PSX.

61. Pompian, M. M. (2011). Behavioral finance and wealth management: how to build investment strategies that account for investor biases, John Wiley \& Sons. https://doi.org/10.1002/9781119202400

62. Pompian, M. M. (2012). Behavioral finance and investor types: managing behavior to make better investment decisions, John Wiley \& Sons. https://doi.org/10.1002/9781119202417

63. Quddoos, M. U., et al. (2020). Impact of Behavioral Biases on Investment Performance in Pakistan: The Moderating Role of Financial Literacy. Journal of Accounting and Finance in Emerging Economies, 6(4), 1199-1205. https://doi.org/10.26710/jafee.v6i4.1512

64. Rasool, N. and S. Ullah (2020). Financial literacy and behavioural biases of individual investors: empirical evidence of Pakistan stock exchange. Journal of Economics, Finance and Administrative Science. 25(50), 261278. https://doi.org/10.1108/JEFAS-03-2019-0031

65. Ricciardi, V. (2008). Risk: Traditional finance versus behavioral finance. Handbook of finance 3, John Wiley and Sons, Inc. https://doi.org/10.1002/9780470404324.hof003002

66. Rosenberg, M. (1968). The logic of survey analysis, Basic Books Inc.

67. Schmidt, M. (2004). Investigating risk perception: a short introduction. Loss of agro-biodiversity in Vavilov centers, with a special focus of genetically modified organisms (GMOs), edited by: Schmidt, M., Ph. D. Thesis, Vienna.

68. Sekaran, U. and R. Bougie (2016). Research methods for business: A skill building approach, John Wiley \& Sons.

69. Shafi, H., et al. (2011). Relationship between risk perception and employee investment behavior. Journal of Economics and Behavioral Studies, 3(6), 345-351. https://doi.org/10.22610/jebs.v3i6.289

70. Shah, I. and I. R. Malik (2021). The Impact of Over Confidence, Loss Aversion and Regret Aversion on Investors Trading Frequency: Empirical Evidence of Pakistan Stock Exchange. Journal of Managerial Sciences, 15(1), 82-100.

71. Shah, S. Z. A., et al. (2018). Heuristic biases in investment decision-making and perceived market efficiency. Qualitative Research in Financial Markets. https://doi.org/10.1108/QRFM-04-2017-0033

72. Shane, S. and S. Venkataraman (2000). The promise of entrepreneurship as a field of research. Academy of management review, 25(1), 217-226. https://doi.org/10.5465/amr.2000.2791611

73. Sharpe, W. F. (1964). Capital asset prices: A theory of market equilibrium under conditions of risk. The journal of finance, 19(3), 425-442. https://doi.org/10.1111/j.1540-6261.1964.tb02865.x

74. Shefrin, H. (2010). "How psychological pitfalls generated the global financial crisis." Voices of Wisdom: Understanding the Global Financial Crisis, Laurence B. Siegel, ed., Research Foundation of CFA Institute: 1004. https://doi.org/10.2139/ssrn.1523931

75. Shefrin, H. (2016). Behavioural insights for improving the practice of risk management. Journal of risk management in Financial Institutions, 9(2), 112-119.

76. Shehata, S. M., et al. (2021). The Moderating Role of Perceived Risks in the Relationship between Financial Knowledge and the Intention to Invest in the Saudi Arabian Stock Market. International Journal of Financial Studies, 9(1), 9. https://doi.org/10.3390/ijfs9010009

77. Smith, S. M. (2013). Determining sample size. Retrieved February 23: 2017. https://doi.org/10.1007/s10603$\underline{011-9165-6}$

78. Spindler, G. (2011). Behavioural finance and investor protection regulations. Journal of Consumer Policy, 34(3), 315-336.

79. Sutha, T. (2016). Psychological Biases and its Impact on Trading Behaviour.

80. Trang, P. T. M. and N. H. Tho (2017). Perceived risk, investment performance and intentions in emerging stock markets. International Journal of Economics and Financial Issues, 7(1), 269-278.

81. Tversky, A. and D. Kahneman (1992). Advances in prospect theory: Cumulative representation of uncertainty. Journal of Risk and uncertainty, 5(4), 297-323. https://doi.org/10.1007/BF00122574

82. Yao, J. and D. Li (2013). Bounded rationality as a source of loss aversion and optimism: A study of psychological adaptation under incomplete information. Journal of Economic Dynamics and Control, 37(1), 1831. https://doi.org/10.1016/j.jedc.2012.07.002

83. Yuliani, Y., et al. (2017). Risk perception and psychological behavior of investors in emerging market: Indonesian stock exchange. Investment Maangement and Financial Innovations, 14(2), 347-358. https://doi.org/10.21511/imfi.14(2-2).2017.06

84. Zahera, S. A. and R. Bansal (2018). Do investors exhibit behavioral biases in investment decision making? A systematic review. Qualitative Research in financial markets, 10(2), 210-251. https://doi.org/10.1108/QRFM$\underline{04-2017-0028}$ 